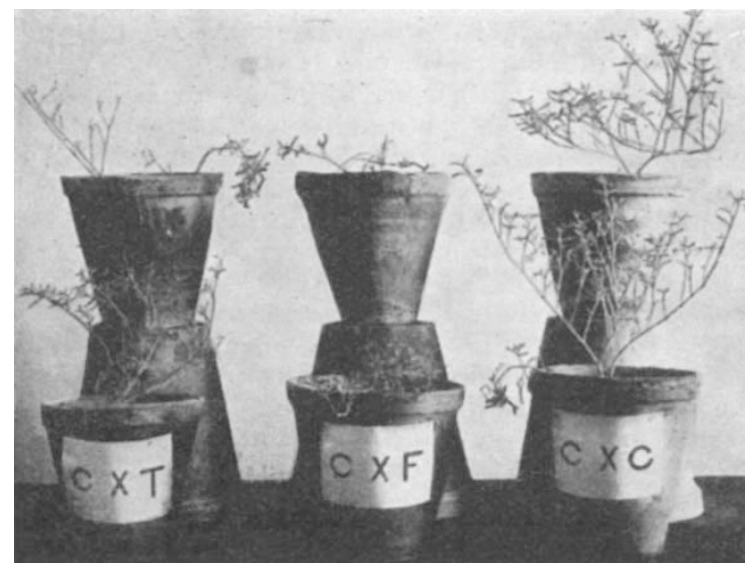

Fig. 2. Zygophyllum coccineum plants cross-inoculated with arabica $(C \times F)$, or with its own nodular bacterium $(C \times C)$; the plants are about one year old

The type of growth and stimulation of noduleformation in Zygophyllum coccineum, in response to either its own specific nodular bacterium or to those isolated from 1 ribulus alatus and Fagonia arabica, are represented photographically (Fig. 2). The plant did not show a decided benefit except in presence of its own specific bacterium ; it grows green and healthy, and it blossoms at a comparatively early stage. On the other hand, the cross-inoculated plants showed weak and stunted growth; this is followed by yellowing and death of some branches, and a complete cessation of flower-formation. Similarly, no nodulation was found to occur except in plants inoculated with the specific nodular bacterium. This may indicate a sort of specificity between Zygophyllum coccineum and its nodule-forming bacterium.

Further work concerning the growth responses of other zygophyllaceous and leguminous genera to different root-nodule bacteria, as well as the morphological and physiological characters of various bacterial isolates, is still in progress.

M. A. Mostafa

M. Z. MahmodD

Faculty of Science,

Fouad I University,

Cairo.

Nov. 6.

${ }^{1}$ Sabet, Y. S., Nature, 157, 656 (1946).

\section{Experimental Evidence of the Patho- genicity of Fusarium oxysporum Schl. f. to the Oil Palm (Elæis guineensis J.)}

IN 1946 and 1948 Wardlaw $^{1}$ reported the widespread occurrence of a vascular wilt disease of the oil palm in the Belgian Congo and Nigeria, closely comparable strains of Fusarium oxysporum Schl. f. being consistently isolated from the necrosed wood-vessels of palms of all ages, including seedling palms $1-2$ years old. The morphology and physiology of the fungus have been investigated by Gogoi ${ }^{2}$ and its appearance in the wood-vessels described by Kovachich ${ }^{3}$.

Evidence of the pathogenicity of the fungus isolated has been sought in a number of inoculation experiments. These will be described in detail else- where; here it will be sufficient to indicate the conditions under which proof of pathogenicity has been obtained. Oil palm seedlings of a Tenera-Dura cross were germinated and transplanted in seed-beds. Vigorous, well-developed seedlings, at the two-leaf stage, were selected for experimontal treatment. 'The root system was washed in water. The method of inoculation consisted in dipping the washed root system in a diluted Richard's solution culture of the fungus. The seedlings were then planted, in groups of four, in zinc cylinders $(20 \mathrm{~cm}$. diam. $\times$ $18 \mathrm{~cm}$. deep, with a hole in the bottom) containing about five litres of soil previously sterilized by chloropicrine or by treatment with steam. The pots, four inoculated and two controls in each series, were protected under an aluminium-sheet roof, and watered every other day.

About forty days after inoculation some leaf yellowing, desiccation, and browning could be observed in the inoculated seedlings, the controls being dark green and healthy. These symptoms increased so that two months after inoculation many of the inoculated seedlings were seriously affected and some were dead. The control plants still remained healthy. The inoculated plants showed both diseased and healthy roots, and necrotic vascular strands could be traced from the roots into the shoot or 'bulb'. No such discolorations were evident in the 'bulbs' of the control plants. On being cultured, the necrotic 'bulb' tissue yielded only pure cultures of $F$. oxysporum. From diseased roots the pathogen was rarely obtained alone. On no occasion was Fusarium isolated from the control seedlings. These findings were confirmed in other experiments.

The results obtained show: (1) that Fusarium oxysporum is pathogenic to the oil palm, causing rotting of roots and a necrosis of the wood-vessels in the shoot; (2) that the method of inoculation described above may afford a means of investigating the reaction of seedling palms to this pathogen.

J. V. FRASELLE

Laboratoire Central de Phytopathologie,

Institut National pour l'Étude

Agronomique du Congo Belge, Yangambi, Belgian Congo. Jan. 5.

${ }^{1}$ Wardlaw, C. W., Nature, 158, 56, 712 (1946) ; 162, 850 (1948).

${ }^{2}$ Gogoi, T., Trans. Brit. Mycol. Soc., 32, 171 (1949); 33, 121 (1980).

${ }^{3}$ Kovachich, W. G., Ann. Bot., N.S., 12, 327 (1948).

\section{Terramycin and Spironema duttoni Infections}

IN the course of experiments with terramycin upon various laboratory infections, we have found that the drug has a powerful effect on Spironema duttoni in mice. The animals were inoculated intraperitoneally with a suspension of blood from a heavily infected mouse. Untreated mice usually died in three to six days; occasionally a mouse survived and the infection pursued a relapsing course. Treatment with terramycin was given on the day after infection, either by subcutaneous injection or by stomach tube.

A single subcutaneous dose of $12.5 \mathrm{mgm} . / \mathrm{kgm}$. of terramycin caused all the mice to survive; but the parasites reappeared in the peripheral blood six days later. With $25 \mathrm{mgm}$. $/ \mathrm{kgm}$. all of the mice were cured, and none relapsed over a period of nine weeks. Suspensions of liver, spleen and brain of these animals 